\title{
ORIGINAL ARTICLE \\ Effect of and satisfaction with www.elearnSCl.org for training of nurse students: a submodule pilot study
}

\author{
$\mathrm{N} \mathrm{Liu}{ }^{1}, \mathrm{X}-\mathrm{W} \mathrm{Li}{ }^{1}, \mathrm{M}-\mathrm{W}$ Zhou $^{1}, \mathrm{AV}$ Krassioukov ${ }^{2}$ and F Biering-Sørensen ${ }^{3}$
}

\begin{abstract}
Study design: Interventional training session.
Objective: To investigate the effect and satisfaction with didactic training using printed text of a submodule of www.elearnSCl.org for nurse students and to assess the answers of each question.

Setting: A Peking University teaching hospital.

Methods: Twenty-eight nurse students in two groups (14 in each) were involved. Only group A received a translated print-out of the slides from the 'Nursing management' submodule in www.elearnSCl.org for 1-h self-study before the class. At the beginning of class, both groups were tested using the self assessment questions. Then, a lecture according to the content of this submodule was carried out and afterwards both groups answered the self assessment questions again. Finally, both groups filled in a training course satisfaction questionnaire.
\end{abstract}

Results: At the beginning of the class, the mean score (max 9 ) of the self assessment in group $A$ was $7.1 \pm 1.1$, which was significantly higher than that in group $B(4.9 \pm 1.7, P=0.001)$. After the lecture, the mean score of the self assessment in group $A$ had insignificantly increased to $7.4 \pm 1.3$, whereas in group B it increased significantly to $6.9 \pm 0.8(P<0.001)$. The mean score $($ max 50 ) of the training course satisfaction questionnaire was $42.8 \pm 5.2$. Sixty-four percentage of the students indicated that they were very satisfied (overall score $\geqslant 42$ ) with the training and no students were unsatisfied (overall score $<30$ ).

Conclusion: Self-study and lecture presentation are effective methods for training the content of www.elearnSCl.org to nurse students. The training satisfaction of this submodule within the www.elearnSCl.org is favorable.

Spinal Cord (2014) 52, 774-778; doi:10.1038/sc.2014.119; published online 29 July 2014

\section{INTRODUCTION}

Education and training of the multidisciplinary team involved in the management of individuals with spinal cord injury (SCI) is one of the primary goals for the International Spinal Cord Society (ISCoS). Therefore, the Education Committee of ISCoS took initiative to develop the e-learning program www.elearnSCI.org on comprehensive management of individuals with spinal cord lesions for all members of the team for worldwide access. ${ }^{1}$ This is a web-based educational resource, which is available free of charge worldwide following registration. By creating an account, the user will gain full access to all the features of the website.

Totally seven modules constitute the www.elearnSCI.org: 'Overview for the whole team', and for 'Doctors', 'Physiotherapists', 'Nurses', 'Prevention', 'Psychologists, social workers and peer counselors', and 'Occupational therapists and assistive technologists'. Each module consists of a variety of submodules describing a specific topic. The first module entitled 'Overview for the whole team' provides general information essential for all members of the multidisciplinary team. Five of the other six modules are discipline-specific, which have more in depth information for the particular discipline. This structure ensures that the content is directed at the appropriate level for each discipline. ${ }^{2}$ The website www.elearnSCI.org was launched during the 51st Annual Scientific Meeting of ISCoS in London on 4 September
2012. Thus, as an up-to-date educational resource in spinal cord medicine, limited knowledge exists on its training effect and satisfaction in using it by trainees.

In this study, the effect of a training session using a submodule within www.elearnSCI.org by nurse students was examined using the self assessment from the same submodule. However, the translation of printed text was used instead of the online training feature of www.elearnSCI.org for the study because the website is only available in English. In addition, the assessment of answers of individual questions and the satisfaction with this training was investigated.

\section{PARTICIPANTS AND METHODS}

In May 2013, during the teaching workshop of physical medicine and rehabilitation, 28 nurse students in their third year of education were involved in the study. The students were from the Department of Nursing, Health Science Center, Peking University, China.

\section{Training process}

Twenty-eight nurse students were divided into two groups, with 14 in each. Group A received a translated print-out of the slides in the 'Nursing management' submodule within the 'Overview for the whole team' from www.elearnSCI.org for $1 \mathrm{~h}$ self-study before the class. Group B did not get any information of the training material before the class. The translated print-out

${ }^{1}$ Department of Rehabilitation Medicine, Peking University Third Hospital, Beijing, China; ${ }^{2}$ Department of Medicine, International Collaboration on Repair Discoveries (ICORD), University of British Columbia, Vancouver, British Columbia, Canada and ${ }^{3}$ Department for Spinal Cord Injuries, Glostrup University Hospital and Faculty of Health Sciences, University of Copenhagen, Copenhagen, Denmark

Correspondence: Professor M-W Zhou, Department of Rehabilitation Medicine, Peking University Third Hospital, No. 49 North Garden Road, Beijing 100191, China E-mail: zhoumouwang@163.com

Received 8 February 2014; revised 28 April 2014; accepted 19 May 2014; published online 29 July 2014 
was the format of the original material from the website (http://www.elearnsci.org/downloads/126_6.pdf) with six screens printed on one page. For translation of the training material into Chinese, the first author made a formal application to the chair of the Education Committee of ISCoS. After receiving the consent from the chair of the committee, the first author did the initial translation, which afterwards was scrutinized by the second author. The third author made the review and the suggestions and comments, which were evaluated by all three translators/reviewers and the final translation was agreed to. Then at the beginning of class, both groups were tested using the nine selfassessment questions from the same submodule. The questions are in the format of either single answer or multiple answers multiple-choice question. The correct answer was not revealed to the students after this test. Then a lecture using the translated slides from the 'Nursing management' submodule within the 'Overview for the whole team' from www.elearnSCI.org was carried out using the screen in the classroom. Both groups answered the selfassessment questions again after the lecture. During the test before and after the lecture, students in Group A were not permitted to use the print-out of the slides. After the second test, the correct answers were provided for the students. Finally, all students filled in a training course satisfaction questionnaire (see Table 1) at the end of the class. The questionnaire including 10 questions developed to indicate the satisfaction with the training by the trainees.

\section{Outcome measure}

Submodule self-assessment. There are nine self-assessment questions in the submodule of 'Nursing Management' (http://www.elearnsci.org/sa.aspx?id=27; Appendix 1). Among these, three questions are single-answer multiple-choice questions, whereas the other six questions are multiple answers multiple-choice question. The questions are related to the following key knowledge points in the e-learning material: one question about the goals of nursing care, gastrointestinal complications, deep vein thrombosis (DVT) and pulmonary embolism; two questions about respiratory nursing, bladder management and pressure ulcer (PU). The students were asked to complete the self-assessment questions by selecting the appropriate answer/answers. The correct answer/ answers of each question gained a one point score for a total of maximum nine points for all nine questions.

Training course satisfaction questionnaire. A training course satisfaction questionnaire was developed including 10 questions (Table 1). The intent of the questionnaire is to reflect the trainees' perspective on various aspects of the

Table 1 Training course satisfaction questionnaire. Please express your opinion on the various training aspects listed below, by checking the appropriate score, based on the following scale: 1: poor; 2: fair; 3: average; 4: good; 5: very good

\begin{tabular}{|c|c|c|c|c|c|c|}
\hline & Items & 1 & 2 & 3 & 4 & 5 \\
\hline 1 & The objectives of the course have been made clear & & & 3 & 11 & 14 \\
\hline 2 & $\begin{array}{l}\text { The goals of this course were clearly stated at the } \\
\text { beginning }\end{array}$ & & & & 13 & 15 \\
\hline 3 & $\begin{array}{l}\text { The content of the course was relevant in the context } \\
\text { of its goals }\end{array}$ & & & 1 & 11 & 16 \\
\hline 4 & $\begin{array}{l}\text { In my opinion, the objectives of the course have been } \\
\text { accomplished }\end{array}$ & & & 6 & 15 & 7 \\
\hline 5 & $\begin{array}{l}\text { The training course widens my knowledge in the field } \\
\text { of spinal cord injury }\end{array}$ & & & 5 & 15 & 8 \\
\hline 6 & $\begin{array}{l}\text { The questions within the test reflected the key points } \\
\text { in the course }\end{array}$ & & & 4 & 13 & 11 \\
\hline 7 & The time spent on listening the course was reasonable & & & 4 & 9 & 15 \\
\hline 8 & $\begin{array}{l}\text { The topic dealt with is transferable to/useful in daily } \\
\text { practice }\end{array}$ & & & 7 & 6 & 15 \\
\hline 9 & The course met my expectations and satisfaction & & & 8 & 11 & 9 \\
\hline 10 & The overall value of the training course I would rate as: & & & 4 & 14 & 10 \\
\hline
\end{tabular}

training course. The questions within the questionnaire contain the objective, goals, content, test and overall satisfaction of the training course. The response to each question is given on a 5 -point Likert scale: ${ }^{3} 1$ is assigned to be poor, 2 as fair, 3 as average, 4 as good and 5 as very good. Thus, the maximal score was 50. We divided the results of the satisfaction questionnaire into three categories: $42-50$ as very satisfied, $30-41$ as satisfied and less than 30 as unsatisfied.

\section{Statistical analyses}

Statistical analysis was performed by using SPSS 19.0 (SPSS Inc., Chicago, IL, USA) as follows: differences between the means of continuous variables were calculated with Student's $t$-test: a paired test was used between the same students who underwent different tests before and after lecture and an independent test was used between different students in the same test. Significance level was set at $P<0.01$.

\section{RESULTS}

At the beginning of the class, the mean score ( $\max 9)$ of the selfassessment in group A was $7.1 \pm 1.1$, which was significantly higher than that in group $B(4.9 \pm 1.7, P=0.001)$. After the lecture, the mean score of the self-assessment in group A was insignificantly increased to $7.4 \pm 1.3(P=0.27)$, whereas in group $\mathrm{B}$ significantly increased to $6.9 \pm 0.8(P<0.001)$. The difference between the two groups was insignificant after the lecture $(P=0.25)$.

The response accuracies at different time points by the two groups are shown in Table 2. After self-study before the lecture, students from group A presented correct answer in majority of the questions except Q2 for respiratory care (5/14) and Q9 for preventing DVT and pulmonary embolism (4/14). Interestingly, although students from group B did not have self-study before lecture, hence the response accuracies were lower in most of the questions, the accurate response rate in Q2 and Q9 was higher than those in group A (10/14 and 14/ 14, respectively). After the lecture, response accuracies in Q2 (9/14) and Q9 (8/14) were improved in group A. Comparing the results of the test before and after the lecture in group B shows that response accuracies were increased or remained stable in majority of questions.

The satisfaction with the training measured after the lecture indicated that the mean score was $42.8 \pm 5.2$ for the 10-item questionnaire. Among the students, $64 \%$ were very satisfied (overall score $\geqslant 42$ ) with the training, the remaining $36 \%$ of students expressed they were satisfied (overall score between 30 and 41) with the training, whereas no students were unsatisfied (overall score $<30$ ). The results obtained from the satisfaction questionnaire are shown in Table 1.

\section{DISCUSSION}

To our knowledge, this is the first investigation of the training effect of and satisfaction with the www.elearnSCI.org. Among the nine questions within the self-assessment of the 'Nursing management' submodule, the following topics were involved: the goals of nursing care, respiratory nursing, bladder management, PU, gastrointestinal complications, DVT and pulmonary embolism. For the knowledge related to the goals of nursing care tested in Q4, both groups had acceptable response accuracy no matter who had self-study as option $\mathrm{D}$ is obviously incorrect.

Respiratory dysfunction is a major cause of morbidity and mortality in individuals with SCI because of impairment of innervations of respiratory muscles, reduced vital capacity, ineffective cough, reduced lung and chest wall compliance, and excess oxygen cost of breathing due to distortion of the respiratory system. ${ }^{4}$ It is suggested that a respiratory protocol provided regularly and including a combination of treatment techniques is effective in reducing respiratory complications and $\operatorname{cost}^{5} \mathrm{Q} 1$ and $\mathrm{Q} 2$ are related to 
Table 2 Response accuracies at different time points by two groups of the nine self-assessment questions in the 'Nursing Management' submodule (http://www.elearnsci.org/sa.aspx?id = 27)

\begin{tabular}{|c|c|c|c|c|}
\hline \multirow[t]{2}{*}{ Question } & \multicolumn{2}{|c|}{ Before lecture } & \multicolumn{2}{|c|}{ After lecture } \\
\hline & $\begin{array}{c}\text { Group A } \\
\text { (after self-study) }\end{array}$ & $\begin{array}{c}\text { Group B } \\
\text { (no self-study) }\end{array}$ & Group A & Group $B$ \\
\hline Q1. Which of the following is NOT indicated for respiratory nursing? & $14 / 14$ & $6 / 14$ & $14 / 14$ & $10 / 14$ \\
\hline Q2. Which three of the following are true regarding respiratory care of people with $\mathrm{SCl}$ ? & $5 / 14$ & $10 / 14$ & $9 / 14$ & $12 / 14$ \\
\hline Q3. Which of the following are true regarding responsibilities of nurses for bladder management? & $13 / 14$ & $0 / 14$ & $13 / 14$ & $10 / 14$ \\
\hline Q4. The goals of nursing care for patients with acute $\mathrm{SCl}$ include: & $11 / 14$ & $10 / 14$ & $12 / 14$ & $11 / 14$ \\
\hline Q5. Pressure ulcers in people with $\mathrm{SCl}$ occur due to which three of the following: & $12 / 14$ & $4 / 14$ & $11 / 14$ & $9 / 14$ \\
\hline Q6. Risk of pressure ulcers can be minimized by the following measures: & $14 / 14$ & $11 / 14$ & $14 / 14$ & $11 / 14$ \\
\hline Q7. Which three of the following gastrointestinal complications are associated with $\mathrm{SCl}$ ? & $13 / 14$ & $2 / 14$ & $12 / 14$ & $10 / 14$ \\
\hline Q8. Nurses are responsible for all of the following when managing the bladders of patients with $\mathrm{SCl}$ except: & $13 / 14$ & $12 / 14$ & $11 / 14$ & $11 / 14$ \\
\hline Q9. Nursing care for preventing deep vein thrombosis and pulmonary embolism include: & $4 / 14$ & $14 / 14$ & $8 / 14$ & $13 / 14$ \\
\hline
\end{tabular}

Abbreviation: $\mathrm{SCl}$, spinal cord injury.

Fourteen nurse students were in each group.

respiratory nursing. The common respiratory management performed by nurses includes observations, 2-3 hourly position changes, assisted coughing and delivery of prescribed oxygen/nebulizers and so on as described in the e-learning material of this submodule. Thus, Q1 is easy to answer after self-study in which all three correct answers are outlined. In contrast, students with selfstudy encountered difficulty when answering Q2 because of option B, 'suction excessive secretions', although it is also a common procedure performed by nurses; however, it was not mentioned within the e-learning material. In Q2, option A is designed as a confusing option, in which the first part 'observation' is correct. However, the latter part 'maintain strict bed rest' is opposite to the principle '2-3 hourly position changes'. Interestingly, most students who did not have self-study used their basic knowledge to choose option B and were not disturbed by option A. During the lecture presentation, the 'position changes' was emphasized to all the students. In this setting, students from group A were aware of that option A should not be chosen. Hence, they had higher response accuracy with this question. From this perspective, it is recommended that 'suction excessive secretions' could be added in the e-learning material in order to obtain the consistence between the e-learning material and the selfassessment question.

Bladder management is of utmost importance for life expectancy and quality of life in individuals with SCI who developed neurogenic bladder dysfunction, ${ }^{6}$ which is reflected in Q3 and Q8. According to www.elearnSCI.org, nursing management for bladder care consists of the following aspects: monitoring urine output (above $30 \mathrm{ml} \mathrm{h}^{-1}$ ), ensure drainage, maintain adequate hydration and observe for urinary tract infection. For Q8, in the translated version 'except' was added to the end of the original stem (Nurses are responsible for all of the following when managing the bladders of patients with SCI), in order to make it consistent with the correct answer of options. This needs to be addressed in the next update of the www.elearnSCI.org. In Q8, option C 'commencing clean intermittent catheterization as soon as possible' is incorrect. The first phrase 'commencing clean intermittent catheterization' is true, as intermittent catheterization is now accepted as the standard method for the urological management of patients with a neurogenic bladder due to $\mathrm{SCI}^{7,8}$ and is effective in preventing upper urinary tract disease after SCI. ${ }^{9}$ However, the second phrase is not appropriate because it is not consistent with the clinical guideline in which it is necessary to wait until fluid resuscitation is complete before starting intermittent catheterization, which will prevent overdistention of the bladder. ${ }^{10}$

Impaired sensation with loss of normal signals from the skin and underlying structures is the main risk factor for developing PUs after SCI. ${ }^{11}$ Initial medical care management is a significant risk factor for PU development in people with SCI. ${ }^{12}$ It is suggested that PU prevention and management should be core knowledge for all health professionals. ${ }^{13}$ Q5 and Q6 in the self-assessment of this submodule are designed to investigate the knowledge about PU. In comparison with Q6 about PU prevention, Q5 related to risk factors is difficult to answer correctly without self-study or lecture presentation. This is because the principle for PU prevention in the general population can be transferred directly to individuals with SCI. As these nurse students already had knowledge about this issue from their previous lectures on nursing management for individuals at bed rest, question about PU prevention was easier to answer. However, most risk assessment scales for the able-bodied population probably do not provide an optimum identification of SCI patients at risk for PU and might miss important risk factors and might contain risk factors that are irrelevant for this group. ${ }^{14}$ Thus, the correct answering of Q5 requires training by either self-study or specific SCI lecture presentation.

Neurogenic bowel is a colonic dysfunction resulting from a lack of central nervous control commonly observed in individuals with SCI. ${ }^{15}$ Therefore, gastrointestinal complication after SCI is mostly related to the loss of neural control including paralytic ileus, gastroparesis, dysphagia and neurogenic bowel dysfunction. For this reason, students who did not have self-study encountered more difficulty in choosing the correct answers than those who had performed selfstudy, whereas the situation improved in Group B after the lecture.

DVT is one of the major cardiovascular complications after acute SCI. ${ }^{16}$ Evidence is established that external pneumatic compression with gradient elastic stockings and low-dose heparin may be an effective prophylactic regimen in the prevention of DVT in acute SCI. ${ }^{17}$ Early application of pharmacological plus mechanical treatment for DVT prevention produces a marked reduction in such complications. ${ }^{16}$ In Q9, option C 'commencing vigorous passive movements' is wrong as only physical therapy measures, such as range of motion exercise and gentle effleurage, should be encouraged. ${ }^{18}$ Students both with and without self-study did not choose this option. However, option A brings trouble to students who had self-study because 'to be started as advised by physician' is not 
clearly stated in the original 'anti-coagulants' expression in the e-learning material. Moreover, it is suggested that the content within the www.elearnSCI.org shall be consistent with the correct options in the self-assessment question.

Our study has some limitations. First, assessing online training was one of the main objectives of www.elearnSCI.org. However, the webbased e-learning platform is solely provided in English; therefore, the Chinese translation of the learning material could only be presented as a print-out that diminishes the interaction from web-based learning. Secondly, this pilot study only use one submodule from www.elearnSCI.org; thus, we could only reveal the training effect and satisfaction of this submodule. Therefore, there are still numerous submodules within the seven modules of www.elearnSCI.org that need to be investigated. Last, it would be optimal if online training could be compared with didactic training and didactic complimented with online training. These comparisons were not involved in this study and should be carried out in further studies.

\section{CONCLUSION}

Both self-study and lecture presentation are effective methods for presenting the 'Nursing management' submodule from the www.elearnSCI.org to nurse students. However, self-study plus lecture presentation did not reveal significant difference than self-study alone. Knowledge applicable for both the general population and SCI individuals is not difficult to retrieve and answer correctly by the nurse students during self assessment. However, for knowledge specific to SCI, it is essential that they should be transferred either through self-study or lecture presentation. It is also suggested that the content within www.elearnSCI.org shall be consistent with the selfassessment. In addition, the training satisfaction of this submodule within www.elearnSCI.org is favorable.

\section{DATA ARCHIVING}

There were no data to deposit.

\section{CONFLICT OF INTEREST}

The authors declare no conflict of interest.

\section{APPENDIX 1}

Nine self-assessment questions in the 'Nursing Management' submodule (http://www.elearnsci.org/sa.aspx?id=27). Correct option(s) is/are underlined.

Q1. Which of the following is NOT indicated for respiratory nursing?

A. Changing a patient's position 2-3 hourly

B. Assisting a patient's cough

C. Administrating prescribed oxygen/nebulisers

D. Prescribing anti-tussives to suppress a productive cough

Q2. Which three of the following are true regarding respiratory care of people with SCI?

A. Observe and maintain strict bed rest

B. Suction excessive secretions

C. Provide regular assisted coughing

D. Deliver prescribed oxygen/nebulisers and so on

Q3. Which of the following are true regarding responsibilities of nurses for bladder management?

A. Monitor urinary output (above $30 \mathrm{ml} \mathrm{h}^{-1}$ )

B. Ensure adequate drainage
1 Wyndaele JJ. Elearning: the next step in ISCOS's worldwide education on comprehensive spinal cord management. Spinal Cord 2013; 51: 173.

2 Chhabra HS, Harvey LA, Muldoon S, Chaudhary S, Arora M, Brown DJ et al. www.elearnSCl.org: a global educational initiative of ISCoS. Spinal Cord 2013; 51 : $176-182$.

3 Jamieson S. Likert scales: how to (ab)use them. Med Educ 2004; 38 : 1217-1218.

4 Brown R, DiMarco AF, Hoit JD, Garshick E. Respiratory dysfunction and management in spinal cord injury. Respir Care 2006; 51: 853-868.

5 Berney S, Bragge P, Granger C, Opdam H, Denehy L. The acute respiratory management of cervical spinal cord injury in the first 6 weeks after injury: a systematic review. Spinal Cord 2011; 49: 17-29.

6 Anderson KD. Targeting recovery: priorities of the spinal cord-injured population. J Neurotrauma 2004; 21: 1371-1383.

7 Wyndaele JJ. Complications of intermittent catheterization: their prevention and treatment. Spinal Cord 2002; 40: 536-541.

8 Stohrer M, Blok B, Castro-Diaz D, Chartier-Kastler E, Del Popolo G, Kramer G et al. EAU guidelines on neurogenic lower urinary tract dysfunction. Eur Urol 2009; 56: 81-88.

9 Giannantoni A, Scivoletto G, Di Stasi SM, Silecchia A, Finazzi-Agrò E, Micali I et al. Clean intermittent catheterization and prevention of renal disease in spinal cord injury patients. Spinal Cord 1998; 36: 29-32.

10 Consortium for Spinal Cord Medicine. Bladder management for adults with spinal cord injury: a clinical practice guideline for health-care providers. J Spinal Cord Med 2006; 29: 527-573.

11 Karlsson AK, Krassioukov A, Alexander MS, Donovan W, Biering-Sørensen F. International spinal cord injury skin and thermoregulation function basic data set. Spinal Cord 2012; 50: 512-516.

12 Marin J, Nixon J, Gorecki C. A systematic review of risk factors for the development and recurrence of pressure ulcers in people with spinal cord injuries. Spinal Cord 2013; 51: 522-527.

13 Gupta N, Loong B, Leong G. Comparing and contrasting knowledge of pressure ulcer assessment, prevention and management in people with spinal cord injury among nursing staff working in two metropolitan spinal units and rehabilitation medicine training specialists in a three-way comparison. Spinal Cord 2012; 50: 159-164.

14 Verschueren JH, Post MW, de Groot S, van der Woude LH, van Asbeck FW, Rol M. Occurrence and predictors of pressure ulcers during primary in-patient spinal cord injury rehabilitation. Spinal Cord 2011; 49: 106-112.

15 Krassioukov A, Eng JJ, Claxton G, Sakakibara BM, Shum S. Neurogenic bowel management after spinal cord injury: a systematic review of the evidence. Spinal Cord 2010; 48: 718-733.

16 Aito S, Pieri A, D’Andrea M, Marcelli F, Cominelli E. Primary prevention of deep venous thrombosis and pulmonary embolism in acute spinal cord injured patients. Spinal Cord 2002; 40: 300-303.

17 Merli GJ, Crabbe S, Doyle L, Ditunno JF, Herbision GJ. Mechanical plus pharmacological prophylaxis for deep vein thrombosis in acute spinal cord injury. Paraplegia 1992; 30: 558-562.

18 Agarwal NK, Mathur N. Deep vein thrombosis in acute spinal cord injury. Spinal Cord 2009; 47: 769-772.

C. Maintain adequate hydration by providing sufficient fluids

D. Observe for urinary tract infection

E. all of the above

Q4. The goals of nursing care for patients with acute SCI include: A. Contribute to effective rehabilitation and optimum functional recovery

B. Provide knowledge to people with SCI, their families and caregivers about SCI

C. Promote physical and psychological well-being in the long-term management of people with SCI

D. Get involved in patients' personal problems and try to solve them

Q5. Pressure ulcers in people with SCI occur due to which three of the following:

A. Loss of sensation

B. External pressure

C. Spasticity

D. Impaired blood flow and edema

Q6. Risk of pressure ulcers can be minimized by the following measures: 
A. Changing patients' position every $2-3 \mathrm{~h}$

B. Maintaining constant skin moisture

C. Using pressure-relieving mattresses/cushions if available

D. Positioning patients to minimize pressure, shear and friction

Q7. Which three of the following gastrointestinal complications are associated with SCI?

A. Paralytic ileus and gastroparesis

B. Dysphagia

C. Neurogenic bowel dysfunction

D. Irritable bowel

Q8. Nurses are responsible for all of the following when managing the bladders of patients with SCI except:
(Note: The last word 'except' is added to the original material.)

A. Maintaining adequate hydration and monitoring urinary output

B. Observing for urinary tract infection

C. Commencing clean intermittent catheteriZation as soon as possible

D. Maintain catheter hygiene

Q9. Nursing care for preventing deep vein thrombosis and pulmonary embolism include:

A. Anti-coagulants to be started as advised by physician

B. Anti-emboli stockings

C. Commencing vigorous passive movements

D. Regular measurement of calf for swelling, warmth and redness. 